\title{
Pulsed Electric Field Treatment of Microalgae: Inactivation Tendencies and Energy Consumption
}

\author{
Si Qin, Igor V. Timoshkin, Member, IEEE, Michelle Maclean, Mark P. Wilson, Member, IEEE, \\ Scott J. MacGregor, Member, IEEE, Martin J. Given, Senior Member, IEEE, John G. Anderson, and Tao \\ Wang
}

\begin{abstract}
Pulsed electric field (PEF) treatment can be used to facilitate microbial cell lysis. The aim of the present work is to investigate this effect of PEF treatment on microalgae. The PEF system used in this work consists of a pulse generator and treatment cell with parallel-plane metallic electrodes. PEF treatment of microalgae, Spirulina, was conducted using $33.3 \mathrm{kV} / \mathrm{cm}$ and $66.7 \mathrm{kV} / \mathrm{cm}$ electric field impulses. The efficiency of the PEF treatment for inactivation of microalgae was assessed by comparison of the growth curves of PEF-treated and un-treated samples. Results showed that growth of microalgae can be stopped by the application of between 100 and 500 high-field impulses with field magnitude $33.3 \mathrm{kV} / \mathrm{cm}$. When the field is increased to a magnitude of $66.7 \mathrm{kV} / \mathrm{cm}$, the growth of microalgae can be stopped by application of 50 impulses. Overall this study confirms that pulsed electric field treatments can be used for the inactivation of algae, and the energy consumption of the $P E F$ process can be reduced by using suspensions with lower electrical conductivity.
\end{abstract}

Index Terms—Pulsed electric field, microalgae, inactivation.

\section{INTRODUCTION}

$\mathrm{H}$ IGH voltage impulses, with durations in the range of $10^{-8}-10^{-4}$ seconds, can be used to generate electro-mechanical stresses in biological membranes, which can, in turn, cause disruption of these membranes [1]. If the applied electric field is higher than a specific critical value, the electroporation process becomes irreversible [2], which inactivates the cell being treated. Pulsed Electric Field (PEF) treatment has been largely investigated for microbial inactivation and applications in the food industry, [3]-[7].

Recently this treatment has attracted attention as a potential process for facilitation of extraction of oil from green microalgae, [8]-[13]. In [8], exponentially-decaying HV pulses with a characteristic decay time of $360 \mathrm{~ns}$, which developed a uniform electric field with a peak magnitude of $45 \mathrm{kV} / \mathrm{cm}$, were used for treatment of green microalgae, Ankistrodesmus falcatus. The PEF treatment cell had a parallel-plane topology and consisted of two stainless steel electrodes. The efficiency of the PEF treatment was assessed by comparison of lipid extraction and by microscopic inspection of an algae cell stained with propidium iodide. PEF treatment with a specific energy of $26 \mathrm{MJ} / \mathrm{kg}$ (dry weight) resulted in $~ 90 \%$ of the algae lysed and in a $130 \%$ increase in lipid yield as compared with untreated algae. The authors of [9] used $1 \mu$ s square impulses for PEF treatment of another type of microalgae, Auxenochlorella. protothecoides. The magnitude of electric field which was generated between two parallel-plane stainless steel electrodes was $35 \mathrm{kV} / \mathrm{cm}$ and the maximum specific energy of $2 \mathrm{MJ} / \mathrm{kg}$ was used in this work. The efficiency of the PEF treatment was assessed by comparison of lipid extraction from the treated and untreated algae. It was shown that PEF treatment with $2 \mathrm{MJ} / \mathrm{kg}$ specific energy resulted in a $500 \%$ increase in lipid yield as compared with untreated samples.

The aim of the present study is to investigate the PEF treatment of another type of green algae, Spirulina, with a higher field magnitude in low-conductivity media in order to examine PEF inactivation efficacy and potential structural damage to microalgae. Square HV impulses of duration $1 \mu \mathrm{s}$ and with a rate of voltage rise of $\sim 500 \mathrm{kV} / \mu$ s were used in this study. The uniformly distributed electric fields with magnitude of $33.3 \mathrm{kV} / \mathrm{cm}$ (similar to [9]), and with a higher magnitude of $66.7 \mathrm{kV} / \mathrm{cm}$ were used. Growth curves obtained from the optical density of algae solutions was used to assess the efficiency of PEF treatment. The energy consumption of PEF treatment was obtained and compared with the literature data.

\section{Development of the PEF TReatment Cell and PEF SYSTEM}

A PEF treatment cell was designed and developed for this study, a schematic diagram being shown in Fig. 1. The circular parallel-plane electrodes were made of stainless steel. The supporting structure of the treatment cell was made of nylon. The inter-electrode gap is $3 \mathrm{~mm}$, with two rubber O-rings used to seal the treatment cell. The liquid suspension of the algae is introduced into the cell through a $1.5 \mathrm{~mm}$ diameter inlet port on the side wall. 


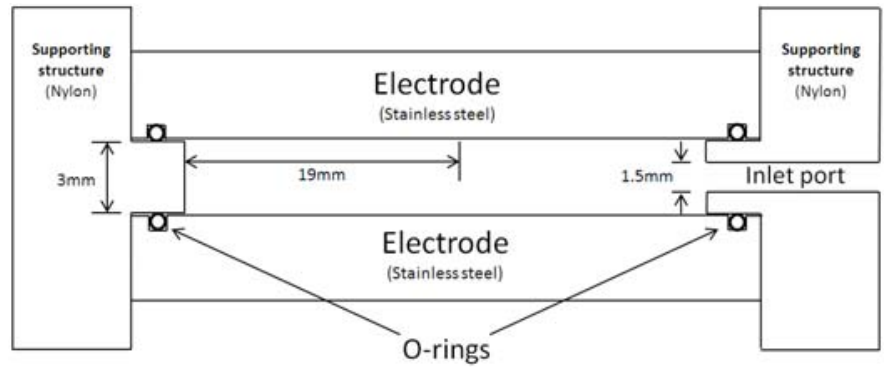

Fig. 1. Cross-sectional view of the PEF treatment cell.

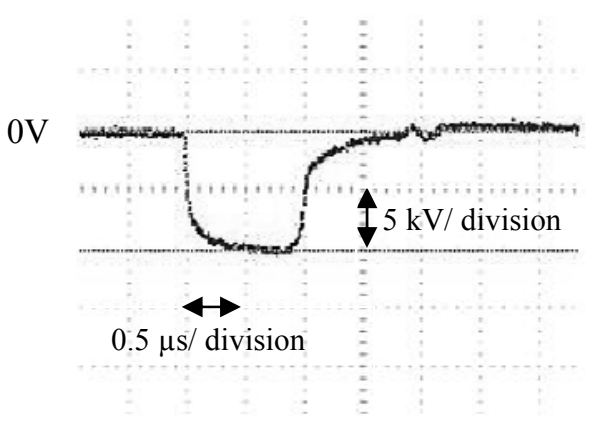

Fig. 2. Voltage waveforms across the PEF treatment cell during the PEF treatment.

The equivalent capacitance, $C$, and resistance, $R$, of the treatment sample were calculated according to:

$$
\begin{aligned}
& R=d / \sigma A \\
& C=\varepsilon_{0} \varepsilon_{r} A / d
\end{aligned}
$$

where $d$ is the separation between the two electrodes, $A$ is the cross-sectional area of the exposed electrode surface, is the conductivity of the liquid suspension, $\varepsilon_{r}$ is the relative permittivity of the liquid suspension and $\varepsilon_{0}$ is the permittivity of free space. For a liquid with conductivity of $20 \mu \mathrm{S} / \mathrm{cm}$ and relative permittivity of 80 , the resistance and capacitance of the treated sample were $1.3 \mathrm{k} \Omega$ and $268 \mathrm{pF}$, assuming that the gap length is $3 \mathrm{~mm}$ and an exposed surface area of $11.34 \mathrm{~cm}^{2}$. The stray capacitance of the treatment cell was $21 \mathrm{pF}$, as measured by a Video Bridge 2160 (Electro Scientific Industries, Inc.). Therefore, the total capacitance of the treatment cell is $289 \mathrm{pF}$. The values of these parameters were used in calculations of the energy consumption of the PEF process.

The pulse generator used in this study was manufactured by SAMTECH Ltd (UK). This transmission-line-based system incorporates a voltage gain network which allowed a voltage equal in magnitude to the charging voltage to be developed across a matched load. The pulse generator produces negative impulses of magnitude $30 \mathrm{kV}$ and duration $1 \mu \mathrm{s}$, and can operate with pulse repetition rate from 0.1 pps (pulses per second) to $10 \mathrm{pps}$.

The pulse generator has an output impedance of $50 \Omega$ when incorporating the voltage gain network. For liquid with conductivity of a few tens of $\mu \mathrm{S} / \mathrm{cm}$, the equivalent resistance was $\sim 1 \mathrm{k} \Omega$. Therefore, a $50 \Omega$ matching resistor was connected in parallel with the PEF treatment cell in order to match the
$50 \Omega$ output impedance of the PEF generator (including voltage gain network). A 1000:1 Tektronix P6015A high voltage probe and a Tektronix TDS 2024 oscilloscope were used to monitor the voltage wave forms. An example of voltage waveform, developed across the PEF cell connected in parallel with the $50 \Omega$ matching resistor is shown in Fig. 2 .

\section{EXPERIMENT PROCEDURE}

The microalgae used in the study were Spirulina green algae, grown for $35-40$ days in a light incubator at $25^{\circ} \mathrm{C}$, under static conditions. The growth media was Zarrouk Medium, [14], which is made up using sterile distilled water supplemented with $\mathrm{NaHCO}_{3}, \mathrm{NaNO}_{3}, \mathrm{NaCl}, \mathrm{K}_{2} \mathrm{SO}_{4}$, and $\mathrm{K}_{2} \mathrm{HPO}_{4}$ (Sigma Aldrich UK). This growth media is highly conductive, with an electrical conductivity of $15-30 \mathrm{mS} / \mathrm{cm}$. To prevent unnecessary dissipation of energy in the solution and reduction of voltage drop across the treatment cell, the Spirulina suspension was centrifuged at $4300 \mathrm{rpm}$ for 10 minutes and re-suspended in distilled water. Washing and re-suspension of the microalgae in distilled water was carried out three times, resulting in significant reduction of the conductivity of the solution: the conductivity of all tested samples was in the range of $22.6 \pm 4.5 \mu \mathrm{S} / \mathrm{cm}$. The concentration of the microalgae in the solution was $13 \mathrm{~g} / \ell$.

The PEF cell containing a suspension of microalgae was connected to the output of the pulse power supply. Two levels of voltage output were used, $10 \mathrm{kV}$ and $20 \mathrm{kV}$, with a pulse repetition rate of $1 \mathrm{pps}$. The resulting electric field strength in the treatment cell was $33.3 \mathrm{kV} / \mathrm{cm}$ and $66.7 \mathrm{kV} / \mathrm{cm}$, respectively. All PEF tests were repeated in triplicate.

Algae samples were subjected to different numbers of $\mathrm{HV}$ pulses: 50, 100, 500 and 1000 . In the case of 500 and 1000 pulses, algae samples were mixed within the treatment cell after every 250 pulses to compensate for any sedimentation effects. After PEF treatment, the treated sample was removed from the treatment cell and $0.1 \mathrm{~m} \ell$ of the treated sample was transferred into $20 \mathrm{~m} \ell$ of fresh growth media and placed in a light incubator at $25^{\circ} \mathrm{C}$. A spectrophotometer (Thermo Spectronic Biomate 5) was used to measure the optical density (absorption) of the sample at $545 \mathrm{~nm}$ every 2 days for 15 days.

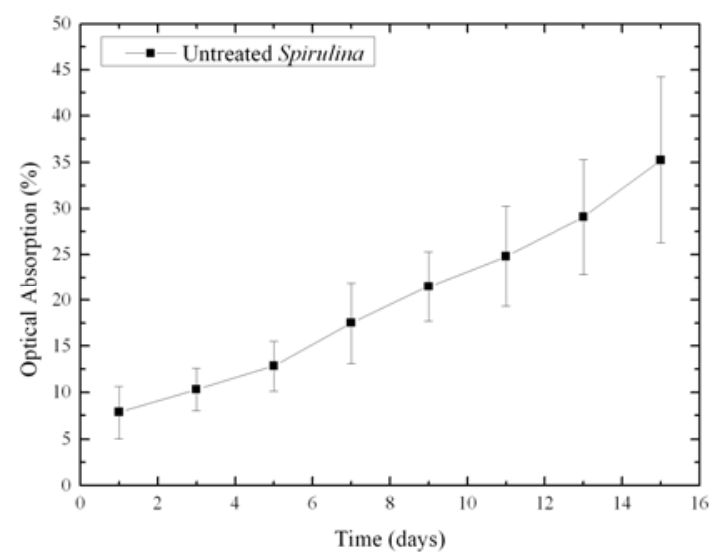

Fig. 3. Growth curve for untreated Spirulina. The Spirulina grew in a light incubator at $25^{\circ} \mathrm{C}$. 
As the Spirulina culture grew, the sample became denser, leading to an increase in the optical absorption. Optical absorption was plotted as a function of time (the growth curve). By comparing the growth curves for treated and untreated (control) samples, the damage caused by the PEF treatment can be estimated. A typical growth curve for untreated algae is shown in Fig. 3.

\section{RESUlTS AND DisCUSSION}

\section{A. PEF Inactivation of Algae}

The results shown in Fig. 4 and Fig. 5 demonstrate that the effect of PEF treatment on microalgae is significant. In the $10 \mathrm{kV}(33 \mathrm{kV} / \mathrm{cm})$ treated group, with 500 or more pulses, no growth was observed by 15 days (optical absorption at day 15 even slightly decreased as compared with day 1, Fig. 4), which suggests that the vast majority of the algae had been inactivated by the applied impulses. With 50 and 100 pulses, optical density at day 15 was in general almost the same as at day 1 and the difference between the optical absorption for growth curves of these two groups of samples treated with 50 and 100 pulses is $\sim 7 \%$. It must be noted that the inactivation efficacy with 50 and 100 pulses at $33 \mathrm{kV} / \mathrm{cm}$ was not consistent: two of the three replicate treatments demonstrated inactivation represented in Fig. 4 and a third run for both 50 and 100 pulses showed algae growth similar to that of the untreated control curve. These results highlight that although 50 and 100 pulses can inactivate the algae, the effect is not consistent with these electrical parameters $(50,100$ pulses at $33 \mathrm{kV} / \mathrm{cm})$, and a larger number of impulses $(500,1000)$ is required to achieve stable inactivation performance.

In the $20 \mathrm{kV}(66.7 \mathrm{kV} / \mathrm{cm})$ treatment (Fig. 5), the effect of the high-voltage impulses was more pronounced. Fig. 5 shows the growth curves for algae treated with 50, 100, 500 , and 1000 impulses and the control (untreated) growth curve. This result indicates that virtually all microalgae have been inactivated after treatment with 50 impulses. Under these field conditions no treated sample showed an increasing optical density, indicating that a reliable inactivation of the algae had been achieved. The results of this study show that inactivation of the microalgae can be achieved using 500 and more pulses at the field level of $33.3 \mathrm{kV} / \mathrm{cm}$. When the field strength is doubled $(66.7 \mathrm{kV} / \mathrm{cm})$, the number of pulses required for inactivation is reduced to $\sim 50$.

\section{B. Temperature Measurement}

To check if the PEF treatment caused significant increases in the sample temperature, which could potentially contribute to microbial inactivation, the temperature of the treated samples was monitored using a thermocouple (Kane-May KM340, K-type) before and immediately after each test. These measurements showed that the PEF treatment regimes used in the present work did not cause significant temperature increase: the maximum registered increase in sample temperature did not exceed $2^{\circ} \mathrm{C}$. This is different from the PEF treatment reported in [8] which resulted in a $50{ }^{\circ} \mathrm{C}$ increase in the temperature of the sample when pre-cooling of the algae suspension and ice-jacket cooling during treatment were employed. In the present study, the absence of temperature increase was a result of the use of the $50 \Omega$ matching resistor in parallel with the treatment cell. The matching resistance is significantly smaller that the resistance of the liquid filled PEF treatment cell $(\sim 1 \mathrm{k} \Omega)$. Therefore, most of the pulse energy was dissipated in the matching resistor rather than in the treated sample.

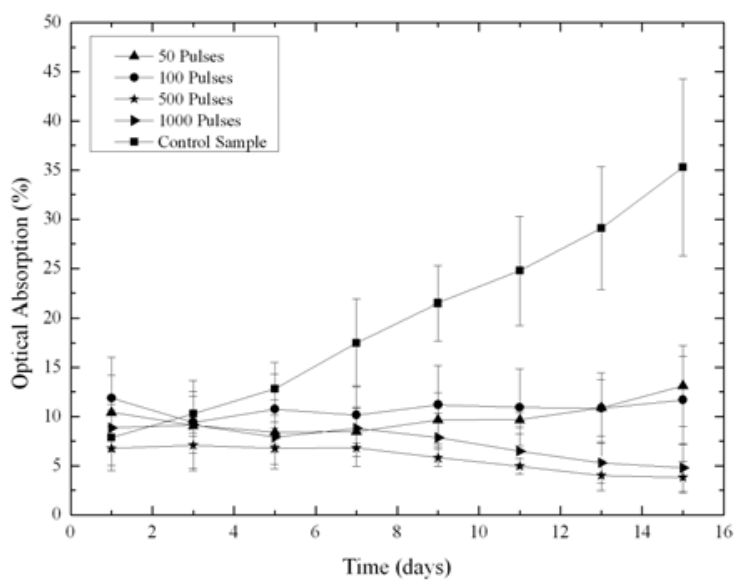

Fig. 4. Growth curves for PEF-treated $(10 \mathrm{kV})$ and a non-treated (control) algae. Data points are the average value of triplicate tests (with the exception of the 50 and 100 pulses groups, in which one outlying group is excluded).

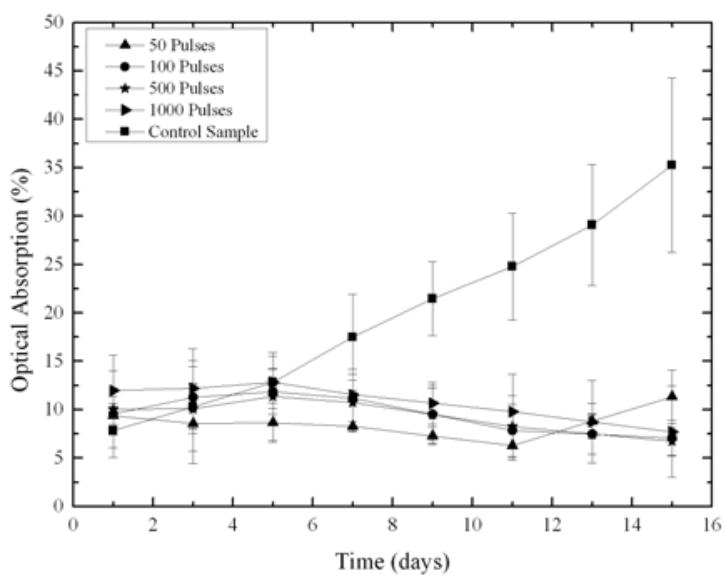

Fig. 5. Growth curves for PEF-treated $(20 \mathrm{kV})$ and a non-treated (control) algae. Data points are the average value of triplicate tests.

\section{Energy Considerations}

The energy consumption during the PEF treatment was estimated by using the equivalent circuit model. The PEF treatment cell was considered to form a parallel $R C$ circuit. The resistance represents the conduction through the solution in the test cell. The capacitance represents the polarisation of the solution within the test cell and can be modelled as an ideal capacitance in series with a resistance, $R_{E S R}$, associated with the losses in these polarisation processes. The energy consumption can therefore be divided into Joule energy dissipation and capacitive energy dissipation. The Joule energy dissipated in the PEF treatment cell, $E_{J}$, is:

$$
E_{J}=N V(t)^{2} t / R
$$


where $N$ is the number of applied pulses, $V(t)$ is the voltage across the treatment cell, $t$ is the pulse duration and $R$ is the equivalent resistance of the treatment cell calculated using Eq.(1). The conductivity of the liquid suspension depends on temperature which should be taken into account in order to ascertain potential changes in the equivalent resistance during the PEF treatment. It has been shown that in the present work the maximum increase in the conductivity due to the PEF treatment does not exceed $\sim 3.6 \%$. Therefore, the constant value of the equivalent resistance obtained by Eq.(1) was used in the energy consumption calculations. It was found that the Joule energy, $E_{J}$, was $0.077 \mathrm{~J}$ per pulse and $0.308 \mathrm{~J}$ per pulse in the case of $10 \mathrm{kV}(33.3 \mathrm{kV} / \mathrm{cm})$ and $20 \mathrm{kV}(66.7 \mathrm{kV} / \mathrm{cm})$ treatment respectively. The energy dissipated in the treatment cell due to displacement current, $E_{C}$, is:

$$
\begin{aligned}
& E_{C}=N \cdot R_{E S R} \cdot \int\left(C \frac{d V(t)}{d t}\right)^{2} \cdot d t \\
& R_{E S R}=\tan \delta /(2 \pi f C)
\end{aligned}
$$

where $N$ is the number of applied pulses, $R_{E S R}$ is the equivalent series resistance of the capacitor in the lumped circuit model, $f$ is the frequency which corresponds to the rise and fall times of the impulse and $C$ is obtained by Eq.(2). The displacement current, $C \cdot d V(t) / d t$, was calculated using the actual voltage waveforms obtained in the tests. The ratio of the imaginary and real parts of permittivity of the suspension, $\tan \delta$, was modelled with the dissipation factor of tap water, which is $1.94 \cdot 10^{-4}$, at $25^{\circ} \mathrm{C}$ for $f=4 \mathrm{MHz}$, according to [15]. This frequency corresponds to the rise and fall times of the impulse shown in Fig.3. The values calculated using Equations (5)-(6) for energy, $E_{C}$ are $0.036 \mathrm{~mJ}$ per pulse at $10 \mathrm{kV}(33.3 \mathrm{kV} / \mathrm{cm})$ and $0.150 \mathrm{~mJ}$ per pulse for $20 \mathrm{kV}(66.7 \mathrm{kV} / \mathrm{cm})$. These are significantly lower that the corresponding Joule energies of $0.077 \mathrm{~J}$ per pulse for $10 \mathrm{kV}(33.3 \mathrm{kV} / \mathrm{cm})$ and $0.308 \mathrm{~J}$ per pulse for $20 \mathrm{kV}(66.7 \mathrm{kV} / \mathrm{cm})$ impulses, respectively. Therefore, the total energy consumption of the PEF treatment can be approximated by the Joule energy losses only. The results of the tests showed that stable inactivation of the microalgae can be achieved by 500 pulses with magnitude of $10 \mathrm{kV}(33.3$ $\mathrm{kV} / \mathrm{cm}$ ). The volume of the treatment cell is $3.4 \mathrm{ml}$, and the concentration of microalgae was $\sim 13 \mathrm{~g} / \ell$, therefore the specific energy required to achieve inactivation of the microalgae is $\sim 0.87 \mathrm{MJ} / \mathrm{kg}$. In the case of $20 \mathrm{kV}(66.7 \mathrm{kV} / \mathrm{cm})$ tests, the number of pulses is reduced to $\sim 50$. The specific energy required to achieve inactivation of the microalgae in this case is $\sim 0.35 \mathrm{MJ} / \mathrm{kg}$.

The specific energy consumption reported in [8] and [9] were $26 \mathrm{MJ} / \mathrm{kg}$ and $2 \mathrm{MJ} / \mathrm{kg}$, respectively. Therefore, the specific energy consumption of the PEF treatment achieved in the present paper is significantly lower than the energy values reported in [8] and [9]. There are several potential reasons which could be responsible for such significant difference in the energy consumption values. First the conductivity of the algae suspension used in this study was significantly lower than that in the previous work as a result of the centrifugation and re-suspension processes that were used resulting in a conductivity of $\sim 20 \mu \mathrm{S} / \mathrm{cm}$. For comparison, the microalgae suspension used in [9] had a conductivity of $0.15 \mathrm{~S} / \mathrm{cm}$. The low conductivity of the suspension used in the present study resulted in a lower conduction current in the treatment cell, and therefore lower energy dissipation. Also, it was reported in [16] that square shaped high voltage impulses result in more efficient inactivation ( $\sim 60 \%$ increase) as compared with double-exponential waveforms. In the present paper, as in paper [9], the square shaped impulses were used, while the authors of paper [8], used double-exponential waveforms. The energy consumption reported in [9] for square, $1 \mu$ s pulses is more than 10-fold lower than the specific inactivation energy reported in [8] for exponentially-decaying impulses with a characteristic decay time of $360 \mathrm{~ns}$. Therefore, further decrease in the PEF specific energy achieved in the present paper (for square, $1 \mu$ s impulses as in paper [9]) can be attributed to other factors, including differences in cellular structure and dimensions of microorganisms. According to the Schwan equation, the field strength induced in the bio-membrane increases with an increase in the external electric field, [17]. It has been shown experimentally in [4], that the yeast Saccharomyces cerevisiae (with linear dimensions of $\sim 6 \mu \mathrm{m}$ ) is more susceptible to the PEF treatment than the bacterium Staphylococcus aureus, with linear dimensions of $\sim 1 \mu \mathrm{m}$. The authors of [17] also attributed an increased susceptibility of the bacterium Bacillus subtilis to the PEF treatment as compared with $S$. aureus to larger size of $B$. subtilis. Although the species of multi-cellular microalgae used in the present work and in papers [8] and [9] are different, linear dimensions of the individual algae cells have the same order of magnitude (10's of $\mu \mathrm{m},[18])$. Therefore, it may be concluded that the size factor does not play a dominant role in the observed reduction in the energy consumption. However, further investigation into exact mechanisms and factors which may result in lower specific inactivation energy is required.

\section{CONCLUSIONS}

The results of this study show that pulsed electric fields can be used to inactivate the microalgae, Spirulina. After appropriate PEF treatment, no growth of the microalgae growth was observed over a 15 day period which indicates that PEF treatment is able to inactivate virtually all microalgae in the sample. When exposed to $\sim 33.3 \mathrm{kV} / \mathrm{cm}$ electric field, stable inactivation can be achieved using at least $\sim 500$ pulses. When exposed to $\sim 66.7 \mathrm{kV} / \mathrm{cm}$ field, significantly smaller number of impulses, $\sim 50$, was required to achieve stable inactivation. The present study also demonstrated that the inactivation of microalgae could be achieved with specific energy of a few hundreds of $\mathrm{kJ} / \mathrm{kg}$ rather than a few or few tens of $\mathrm{MJ} / \mathrm{kg}$ as reported in the literature. This reduction has been achieved by using low-conductivity algae suspensions. Reducing the conductivity of the suspensions also eliminates the heating effect of the PEF treatment. Visual inspection of microalgae did not reveal obvious damage to its structure, however their 
inactivation suggested that some form of changes have been produced by electric field and further study is required to clarify potential structural damage.

\section{REFERENCES}

[1] S. Toepfl, V. Heinz and D. Knorr "Pulsed Electric Fields Technology for the Food Industry: Fundamentals and Applications," Springer-Verlag, 2006.

[2] U. Zimmermann, "Electrical Breakdown, Electropermeabilization and Electrofusion," Rev. Physiol. Biochem. Pharmacol., vol. 105, no. 6, pp. 175-256, 1986.

[3] K. H. Schoenbach, R. P. Joshi, R. H. Stark, F. C. Dobbs, and S. J. Beebe, "Bacterial Decontamination of Liquids with Pulsed Electric Fields," IEEE Trans. on Dielectrics and Electrical Insulation, vol. 7, no. 5, pp. 637-645, Oct. 2000.

[4] B. L. Qin, G. V. Barbosa-Canovas, B. G. Swanson, P. D. Pedrow, and R. G. Olsen, "Inactivating Microorganisms Using a Pulsed Electric Field Continuous Treatment System," IEEE Trans. Industry applications, vol. 34, no. 1, pp. 43-50, Jan/Feb. 1998

[5] J. R. Beveridge, S. J. MacGregor, L. Marsili, J. G. Anderson, N. J. Rowan, and O. Farish, "Comparison of the Effectiveness of Biphase and Monophase Rectangular Pulses for the Inactivation of Micro-Organisms Using Pulsed Electric Fields," IEEE Trans. Plasma Science, vol. 30, no. 4, pp. 1525-1531, Aug. 2002.

[6] J. R. Beveridge, S. J. MacGregor, J. G. Anderson, and R. A. Fouracre, "The Influence of Pulse Duration on the Inactivation of Bacteria Using Monopolar and Bipolar Profile Pulsed Electric Fields," IEEE Trans. Plasma Science, vol. 33, no. 4, pp. 1287-1293, Aug. 2005.

[7] P. S. Brito, H. Canacsinh, J. P. Mendes, L. M. Redondo, and M. T. Pereira, "Comparison between Monopolar and Bipolar Microsecond Range Pulsed Electric Fields in Enhancement of Apple Juice Extraction," IEEE Trans. Plasma Science, vol.40, no. 10, pp. 2348-2354, Oct. 2012.

[8] M. D. A. Zbinden, B. S. M. Sturm, R. D. Nord, W. J. Carey, D. Moore, H. Shinogle, and S. M. Stagg-Williams, "Pulsed Electric Field (PEF) as an Intensification Pretreatment for Greener Solvent Lipid Extraction from Microalgae," Biotechnol. Bioeng., vol. 110, no. 6, pp. 1605-1615, 2013.

[9] C. Eing, M. Goettel, R. Straessner, C. Gusbeth, and W. Frey, "Pulsed Electric Field Treatment of Microalgae-Benefits for Microalgae Biomass Processing," IEEE Trans. Plasma Science, vol. 41, no. 10, pp. 2901-2907, Oct. 2013

[10] R. Straessner, C. Eing, M. Goettel, C. Gusbeth, and W. Frey, "Monitoring of Pulsed Electric Field-Induced Abiotic Stress on Microalgae by Chlorophyll Fluorescence Diagnostic," IEEE Trans. Plasma Science, vol. 41, no. 10, pp. 2951-2958, Oct. 2013.

[11] K. de Boer, N. R. Moheimani, M. A. Borowitzka, and P. A. Bahri, "Extraction and Conversion Pathways for Microalgae to Biodiesel: A Review Focused on Energy Consumption," J. Appl. Phycol., vol. 24, no. 6, pp. 1681-1698, 2012.

[12] M. Vanthoor-Koopmans, R. H. Wijffels, M. J. Barbosa, and M. H. M. Eppink, "Biorefinery of Microalgae for Food and Fuel," Bioresource Technol., vol. 135, pp. 142-149, 2013.

[13] S. Gnapowski, Ruma, H. Akiyama, T. Sakugawa, and M. Akiyama, "Algae Treatment Effects by Pulse Power Discharge in the Water," in Proc. Int. Conf. on Plasma Sci., (ICOPS), pp. 111, 2012.

[14] J. P. Pandey, A. Tiwari and R. M. Mishra, "Evaluation of Biomass Production of Spirulina maxima on Different Reported Media," Journal of Algal Biomass Utilization, vol. 1, no. 3, pp. 70-81, 2010.

[15] T. Meissner, and F. J. Wentz, "The Complex Dielectric Constant of Pure and Sea Water from Microwave Satellite Observations," IEEE Trans. Geoscience and Remote Sensing, vol. 42, no. 9, pp. 1836-1849, Sept. 2004.

[16] B. L. Qin, Q. Zhang, G. V. Barbosa-Canovas, B. G. Swanson, and P. D. Pedrow, "Inactivation of Microorganisms by Pulsed Electric Fields of Different Voltage Waveforms," IEEE Trans. Dielectrics and Electrical Insulation, vol. 1, no. 6, pp. 1047-1057, Dec. 1994.

[17] A. H. El-Hag, S. H. Jayaram, O. R. Gonzalez, and M. W. Griffiths, "The Influence of Size and Shape of Microorganism on Pulsed Electric Field Inactivation," IEEE Trans. Nanobioscience, vol. 10, no. 3, pp. 133-138. Sept. 2011.

[18] M. D. Guiry, (2014, Mar. 17). Algaebase [Online]. Avaliable: http://www.algaebase.org.

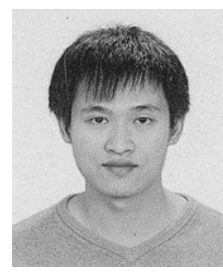

Si Qin was born in Guangxi, China, in 1988. He received the B.Eng. (with honours) degree in Electronic and Electrical Engineering in 2011, and the M.Sc. degree in Electrical Power Engineering with Business in 2012, both from the University of Strathclyde, Glasgow, U.K. $\mathrm{He}$ is currently pursuing the Ph.D. degree in Electronic and Electrical Engineering at the University of Strathclyde.

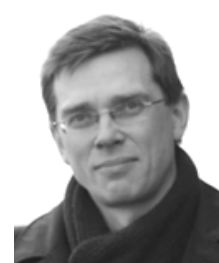

Igor V. Timoshkin (M'07) received the degree in physics from the Moscow State University (Russia) in 1992, and the Diploma and the Ph.D. degree from the Imperial College of Science, Technology and Medicine, (London, UK) in 2001. After graduation from MSU he worked as a Researcher at Moscow State Agro-Engineering University, and then at the Institute for High Temperatures of Russian Academy of Sciences before moving to ICSTM in 1997. He joined the Department of Electronic and Electrical Engineering of the University of Strathclyde (Glasgow, UK) in 2001 where he became a Senior Lecturer in 2011. His research interests include properties of solid and liquid dielectric materials, electronics of plasma discharges in condensed media, practical applications of electro-hydraulic and high-power ultrasound pulses, bio-dielectrics and effects of electromagnetic fields on biological objects.

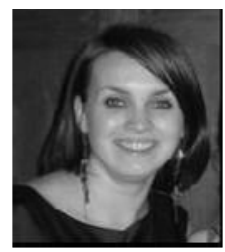

Michelle Maclean was born on the Isle of Lewis, Scotland, in 1980. She received the B.Sc. $\left(1^{\text {st }}\right.$ class honors) degree in Microbiology and Immunology in 2002, and the Ph.D. degree in Electronic and Electrical Engineering in 2006, both from the University of Strathclyde, Glasgow, U.K. She is presently working as a Research Fellow at the Robertson Trust Laboratory for Electronic Sterilization Technologies (ROLEST) at the University of Strathclyde, and her interdisciplinary research work involves the development and application of novel electro-technologies for biological decontamination and sterilization applications in clinical and public health environments. She is a member of The Society for General Microbiology and The American Society of Microbiology.

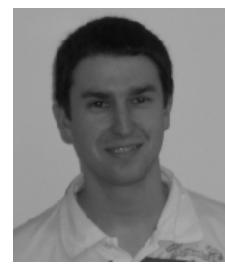

Mark P. Wilson (M'10) was born in Stranraer, Scotland, in 1982. He received the B.Eng. (with honours), M.Phil., and Ph.D. degrees in electronic and electrical engineering from the University of Strathclyde, Glasgow, U.K., in 2004, 2007, and 2011, respectively. He is presently working as a Teaching Associate at the University of Strathclyde, where he continues to investigate surface flashover of solids immersed in insulating oil. Mark is a member of the IEEE Nuclear and Plasma Sciences Society, from whom he received a Graduate Scholarship Award in 2011, the IEEE Dielectrics and Electrical Insulation Society, and the IET.

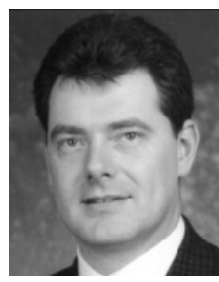

Scott J. MacGregor (M’95) received the B.Sc. and Ph.D. degrees from the University of Strathclyde, Glasgow, U.K., in 1982 and 1986, respectively. He became a Pulsed Power Research Fellow in 1986 and a Lecturer in pulsed-power technology in 1989. In 1994, he became a Senior Lecturer, with a promotion to Reader and Professor of High Voltage Engineering, in 1999 and 2001, respectively. From January 2010 he became a Dean of Engineering Faculty of the University of Strathclyde. His research interests include high-voltage pulse generation, high-frequency diagnostics, high-power repetitive switching, high-speed switching, electronic methods for food pasteurization and sterilization, generation of high-power ultrasound (HPU), plasma channel drilling, pulsed-plasma cleaning of pipes, and stimulation of oil wells with HPU.

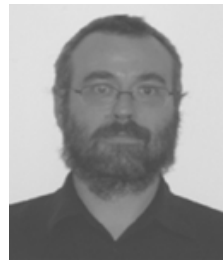

Martin J. Given (M'99-SM'11) is currently a Senior Lecturer in the Department of Electronic and Electrical Engineering at the University of Strathclyde. He received a degree in physics from the University of Sussex in 1981 and a PhD in electronic and electrical engineering from the University of Strathclyde in 1996. 
His research interests include, ageing processes and condition monitoring in solid and liquid insulation systems, high speed switching and pulse power applications.

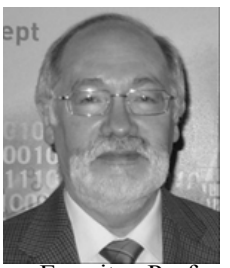

John Anderson was born in Glasgow, U.K., on September 2, 1942. He received the B.Sc. degree in applied microbiology in 1968, and the Ph.D. degree in fungal physiology in 1971, both from the University of Strathclyde, Glasgow. Since 1971, he has been with the Department of Bioscience and Biotechnology, University of Strathclyde, where he became a Professor of Microbiology and Head of Department. He is currently an Emeritus Professor at the University of Strathclyde. His research interests include various aspects of food, biomedical and environmental microbiology with interdisciplinary collaboration on the application of electro-technologies for electronic pasteurization and sterilization.

Tao Wang received the B.Eng and M.Sc degrees from Northeast China Dianli University (China) in 1993 and 1996 respectively, and the Ph.D. degree from the University of Strathclyde (Glasgow, UK) in 2005. He then joined the Newland Entech as a research fellow developing high efficiency industrial ozone generator. He joined the department of Electronic and Electrical Engineering of University of Strathclyde as a lecturer in 2010. His research interests include non-thermal gas discharges and their applications in gas synthesis, water disinfection and advanced oxidation process in water.

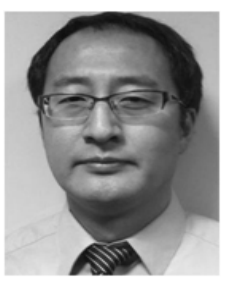

